\title{
Clival fractures in a Level I trauma center
}

\author{
Alexander Winkler-Schwartz, MDCM, ${ }^{1}$ José A. Correa, PhD, ${ }^{2}$ and Judith Marcoux, MD, FRCSC ${ }^{1,3}$ \\ Departments of ${ }^{1}$ Neurology and Neurosurgery, and ${ }^{2}$ Mathematics and Statistics, McGill University; and ${ }^{3}$ Department of \\ Neurosurgery, McGill University Health Centre, Montreal, Quebec, Canada
}

\begin{abstract}
OBJECT Clival fracture (CF) is rare among head traumas. The aim of this study was to explore how radiological features observed in CF reflect the clinical picture and mechanism of injury in such cases.

METHODS Radiological data for patients with skull base fracture admitted to the Montreal General Hospital between February 2002 and October 2012 were obtained from the Quebec Trauma Registry and reviewed for CF. Identified CF was categorized by orientation and quality. Injury mechanism, clinical presentation, and follow-up outcome were obtained through retrospective chart review.
\end{abstract}

RESULTS Of the 1738 patients with skull base fractures, 65 exhibited CF, representing $1.2 \%$ of the 5416 patients with traumatic brain injuries admitted during the period studied. Thirty-nine $(60 \%)$ of the $65 \mathrm{CFs}$ were obliquely oriented, 17 $(26.2 \%)$ were longitudinal, and $9(14 \%)$ were transverse. Twenty-nine $(45 \%)$ of the 65 patients demonstrated linear fracture, $17(26 \%)$ hairline, $10(15 \%)$ diastatic, and 9 (14\%) displaced. Cranial nerve deficits and vascular injury occurred in $13.8 \%$ and $7.7 \%$ of cases, respectively. Twenty-five patients $(38.5 \%)$ died in hospital. The long-term Extended Glasgow Outcome Scale score was significantly lower in transverse compared with longitudinal and oblique fractures $(p=0.03$ and 0.03 , respectively) and lower in diastatic compared with displaced fractures ( $p=0.05)$.

CONCLUSIONS This study provides information on the largest CF population studied to date, expands the current CF classification to include fracture quality as well as orientation, and underscores the existence of significant differences in pathogenesis and clinical presentation of CF subtypes.

http://thejns.org/doi/abs/10.3171/2014.9.JNS14245

KEY WORDS clivus; skull base; trauma

$\mathrm{T}$ HE clivus is the deepest bone of the skull base and is rarely injured, with a fracture incidence reported between $0.21 \%$ and $0.56 \%$ among head traumas. ${ }^{7,29,32,33}$ Because of its rare presentation, much of the literature on clival fractures (CFs) is in the form of case reports, $1,3-5,8,9,11,12,14,15,17,19,21-26,28,34-37,39,41-45,47,48$ with only 5 additional studies describing case series ranging from 9 to 41 cases. $7,20,29,32,33$

Clival fractures carry a high mortality rate; between $24 \%$ and $31 \%{ }^{29,33}$ These injuries usually occur in the setting of severe and multisystem trauma, following a significant mechanism of injury, such as motor vehicle accidents (MVAs), ${ }^{6,721,28,29,39,43}$ pedestrian versus motor vehicle, ${ }^{32,39}$ or falls and crush injuries.,23,44 Since Corradino et al.'s seminal paper on $\mathrm{CF}^{7}$, severity of injury was largely inferred from mechanism of injury as opposed to validated indicators of the extent of trauma (for example, the Injury Severity Score [ISS]). Furthermore, outcome measure- ments were based on mobility, mortality, and neurological status, with no studies including functional outcome status (for example, the Glasgow Outcome Scale [GOS] score) beyond discharge.

Although $\mathrm{CF}$ is traditionally a postmortem diagnosis, the common use of cranial CT in the context of head trauma has allowed for the identification of an increasing number of so-called in vivo cases and has led to the development of a radiographic classification for $\mathrm{CF}$ into either longitudinal, transverse, or oblique orientations. ${ }^{29,32}$ Although classification of the degree of fracture displacement has relevant clinical implications in fractures of the extremities, ${ }^{16}$ spine, ${ }^{46}$ and cranium,,${ }^{13}$ no such system has yet been developed for fractures of the clivus, where minimal displacement is liable to damage closely apposing neurovascular structures.

Many authors have noted a propensity for damage to the posterior circulation in cases of longitudinal frac-

ABBREVIATIONS CF = clival fracture; EGOS = Extended Glasgow Outcome Scale; GCS = Glasgow Coma Scale; IQR = interquartile range; ISS = Injury Severity Score; $M V A=$ motor vehicle accident; $T B I=$ traumatic brain injury.

SUBMITTED January 31, 2014. ACCEPTED September 3, 2014.

INCLUDE WHEN CITING Published online October 24, 2014; DOI: 10.3171/2014.9.JNS14245.

DISCLOSURE The authors report no conflict of interest concerning the materials or methods used in this study or the findings specified in this paper. 
tures $3,7,12,33,41,44$ and damage to the anterior circulation and surrounding cranial nerves in oblique or transverse fractures, ${ }^{7,24,29,33}$ however, defining clinical presentations according to $\mathrm{CF}$ orientation remains inconsistent in the literature. The objective of this study was therefore to introduce a system of CF classification according to degree of displacement as well as orientation, and to determine if clinical presentation, course, and outcome differ among these unique fracture subtypes.

\section{Methods}

The Montreal General Hospital, which is part of the McGill University Health Center, is one of only three adult tertiary (Level I) trauma centers serving the province of Quebec, Canada, which has a population of approximately 8 million people. Based on the "Institut de la Statistique du Québec" and the Health and Social Services Department of Quebec's statistics database, the 2006 adult population covered in the reference territory of the McGill University Health Centre Level I trauma center was $1,125,425 . .^{40}$ As a first step, the Montreal General Hospital Traumatic Brain Injury (TBI) Database and the Trauma Registry Database, a province-wide registry that has been shown to capture more than $85 \%$ of cases of severe pathology, including TBI, ${ }^{30}$ were used to identify all patients admitted with a diagnosis of skull base fracture between February 2002 and October 2012. A total of 1738 patients were initially identified, and radiographic imaging review was performed in all of these patients. Admission and follow-up CT images (axial, sagittal, and coronal views, when available) and reports were reviewed to identify the CF. The institutional ethics review board and the Director of Professional Services approved this study and the informed consent requirement was waived.

On CT imaging, CFs were classified in 2 stages: 1) CFs were categorized according to orientation (longitudinal, oblique, or transverse), as described by Ochalski et al., ${ }^{33}$

2) CFs were also categorized according to fracture quality (hairline, linear, diastatic, or displaced) by the authors (see Figs. 1-3 for examples of each). Hairline fractures were defined as fracture lines $0.1-0.2 \mathrm{~mm}$ wide; linear fractures as fractures of $0.3-0.5 \mathrm{~mm}$ wide; diastatic fractures as a distance between fragments of more than 0.5 $\mathrm{mm}$; and displaced fractures as translational and/or angular displacement of cortical lines. Data collected on imaging also included the presence of associated skull and/or cervical spine fracture, intracranial hemorrhage, and herniation of neural structures. If available, CT angiograms of the neck and cerebral circulation were reviewed for the presence of vascular injury.

A retrospective chart review was performed on patients with identified CF. Information on sociodemographic descriptors, mechanism of injury, presenting physical findings, and interventions during hospitalization was collected. The ISS ${ }^{2}$ was obtained from the Quebec Trauma Registry and the TBI Database. The Extended GOS $(\text { EGOS })^{18}$ was used to characterize the outcome at the patients' most recent follow-up.

\section{Statistical Analyses}

We report descriptive statistics as counts and percentages for categorical variables. For continuous variables we report means \pm SDs if there was evidence that the distribution of values followed a normal pattern, and median and interquartile range (IQR) otherwise. The differences in means among $\mathrm{CF}$ orientation and $\mathrm{CF}$ quality were investigated separately for each outcome by using the EGOS, Glasgow Coma Scale (GCS), and ISS. Because less force is required to cause injury as a person ages, ${ }^{31}$ an ANCOVA was performed to adjust for age. The assumption of homogeneity of linearity for the ANCOVA model was checked by introducing and testing an interaction effect term between group and pretest scores. The assumptions of normality and equal variances of errors, as well as the presence of possible outliers, were explored with analysis of residuals. Where warranted, post hoc pairwise comparisons were performed by $\mathrm{CF}$ orientation and by CF quality, calculating and contrasting all pairs of means. The $\mathrm{p}$ values and $95 \%$ confidence intervals were adjusted for multiplicity of testing by using the Tukey-Kramer method. All hypothesis tests were 2-sided and were performed at the 0.05 level of significance. All analyses were done using SAS, version 9.2 (SAS Institute, Inc.).

\section{Results \\ Incidence of CFs}

Of the 1738 radiographic cases screened, $4.7 \%$ were excluded because imaging was unavailable. Of the remaining $1655,96.1 \%$ were excluded because there was no evidence of $\mathrm{CF}$ on imaging. Thus, 65 cases of $\mathrm{CF}$ were identified, representing $1.2 \%$ of the 5416 patients with TBIs admitted between February 2002 and October
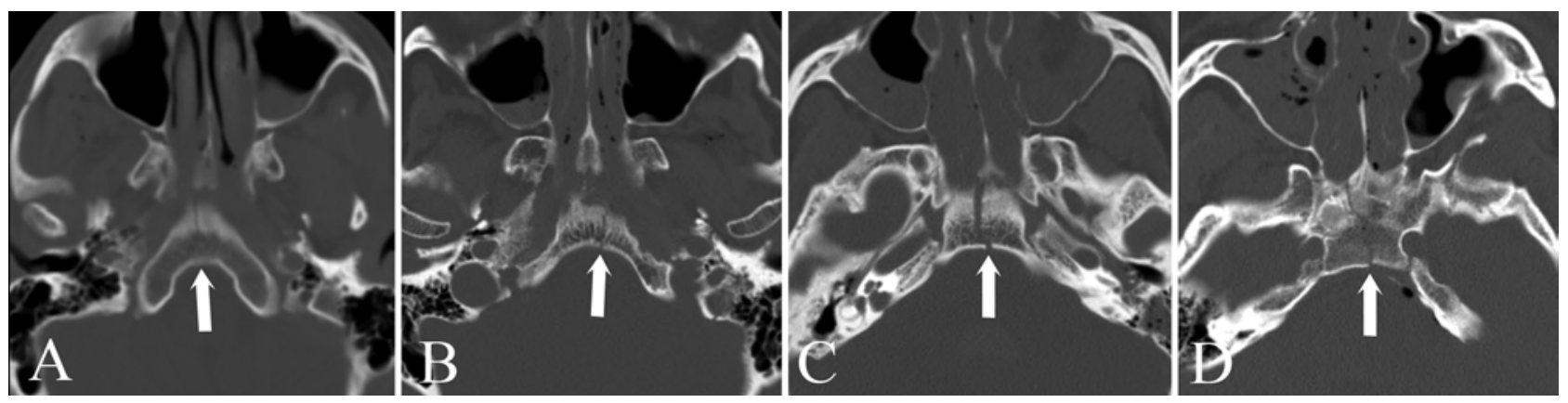

FIG. 1. Bone window of CT scan showing longitudinal CF subtypes. Arrows denote fracture line origin and orientation of overall fracture path. A: Hairline. B: Linear. C: Diastatic. D: Displaced. 

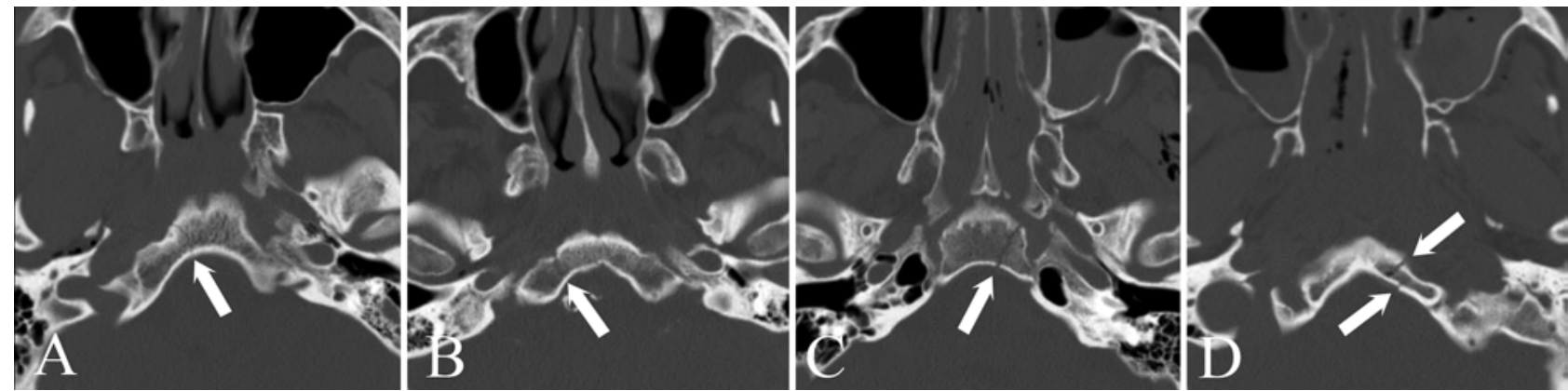

FIG. 2. Bone window of CT scan showing oblique CF subtypes. Arrows denote fracture line origin and orientation of overall fracture path. A: Hairline. B: Linear. C: Diastatic. D: Displaced.

2012. This represents a prevalence of 5.8 per 100,000 of population over a period of 10 years. Figure 4 illustrates how patient selection was performed.

Classification of $\mathrm{CF}$ into groups based on orientation revealed $17(26.1 \%)$ longitudinal, $39(60 \%)$ oblique, and 9 (13.8\%) transverse. Classification of CF based on quality revealed $17(26.1 \%)$ hairline, $29(44.6 \%)$ linear, 10 (15.4\%) diastatic, and $9(13.8 \%)$ displaced. Figure 5 presents the distribution of $\mathrm{CF}$ quality type among $\mathrm{CF}$ orientation. The most commonly occurring $\mathrm{CF}$ was an obliquely oriented linear fracture, representing 21 cases (32.3\%).

\section{Cohort Characteristics}

Table 1 presents the characteristics of the cohort. Within each mechanism of injury group, the most common fracture (oblique linear) occurred in $3(50 \%)$ falls from own height, 7 (28\%) falls from height, $6(46 \%)$ pedestrians struck by motor vehicles, 4 (26.6\%) MVAs, and $1(25 \%)$ assault. Within each type of fracture orientation, MVAs (either vehicle vs vehicle or pedestrian vs vehicle), accounted for 7 (41.2\%) of longitudinal fractures, 15 $(38.5 \%)$ of oblique fractures, and $6(66.7 \%)$ of transverse fractures. Within each type of fracture quality, MVAs represented 5 (29.4\%) of hairline, 13 (44.8\%) of linear, 6 $(60 \%)$ of diastatic, and $4(44.4 \%)$ of displaced fractures.

All cases of transversely oriented fractures and all cases of diastatic fractures studied presented with a GCS score of 8 or less.

\section{Associated Injuries}

Table 2 presents the associated injuries in the cohort. On secondary survey, periorbital ecchymosis was observed in 8 cases (12.3\%) and mastoid ecchymosis in 2 cases (3\%). A CSF leak occurred in 5 cases (7.7\%); 2 (3\%) were CSF rhinorrhea in a longitudinal hairline and oblique diastatic fracture; 2 (3\%) were CSF otorrhea in an oblique hairline and linear fracture; and $1(1.5 \%)$ was subcutaneous frontal in a longitudinal diastatic fracture. Frontal fractures occurred in 10 (58.8\%) longitudinal, 6 (15.4\%) oblique, and $2(22.2 \%)$ transverse fractures. Temporal/petrous fractures occurred in $7(41.2 \%)$ longitudinal, $16(41 \%)$ oblique, and $8(88.9 \%)$ transverse fractures. Occipital fractures occurred in $11(64.7 \%)$ longitudinally, $35(89.7 \%)$ obliquely, and $5(55.6 \%)$ transversely oriented fractures. Hemorrhagic contusions occurred in 13 (76.5\%) hairline, $24(82.8 \%)$ linear, 9 (90\%) diastatic, and $7(77.8 \%)$ displaced. Brainstem hemorrhage occurred in $12(18.4 \%)$ cases, of which 2 (11.8\%) occurred in hairline, $6(20.7 \%)$ in linear, $3(30 \%)$ in diastatic, and $1(11.1 \%)$ in displaced CFs; there were 3 (33.3\%) cases of transverse, $4(23.5 \%)$ of longitudinal, and $5(12.8 \%)$ of oblique fractures. Tonsillar herniation occurred in $1(5.8 \%)$ of longitudinal, $5(12.8 \%)$ oblique, and $3(33.3 \%)$ of transversely oriented fractures; of these, 4 (13.7\%) had linear, 2 (20\%) diastatic, and $3(33.3 \%)$ displaced fracture qualities.

Table 3 outlines the cases of cranial nerve deficits and vascular injury. CT angiography was the sole method for assessing vascular injury and was performed in 43 cases $(66.2 \%)$.

\section{Surgical Interventions}

Table 4 presents the interventions performed among patients in the cohort. Decompressive craniectomy was the single most common surgical intervention carried out
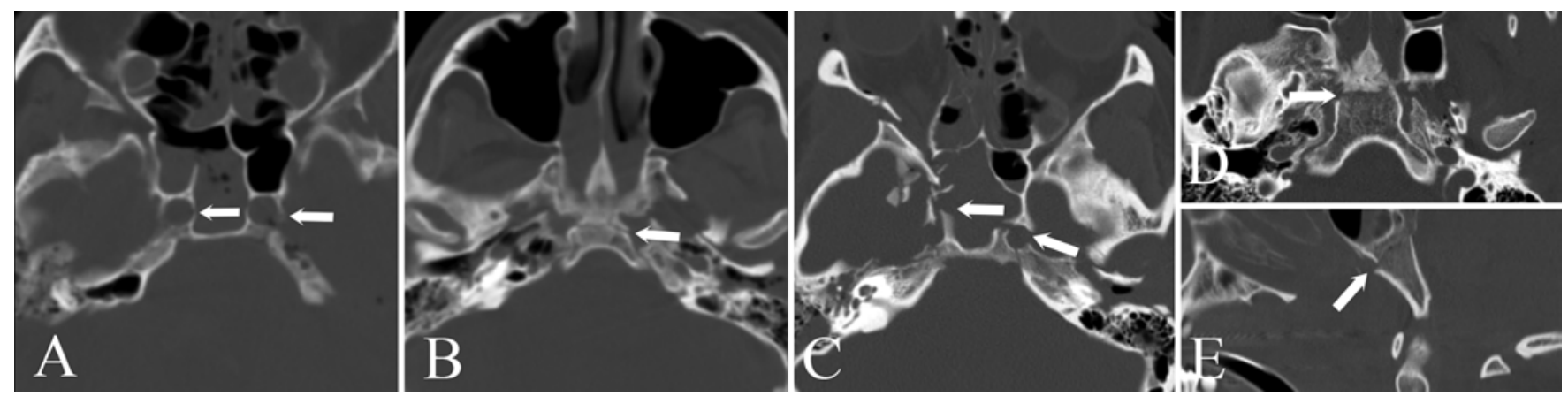

FIG. 3. Bone window of CT scan showing transverse clival fracture subtypes. Arrows denote fracture line origin and orientation of overall fracture path. A: Hairline. B: Linear. C: Diastatic. D: Displaced, axial view. E: Displaced, sagittal view. 


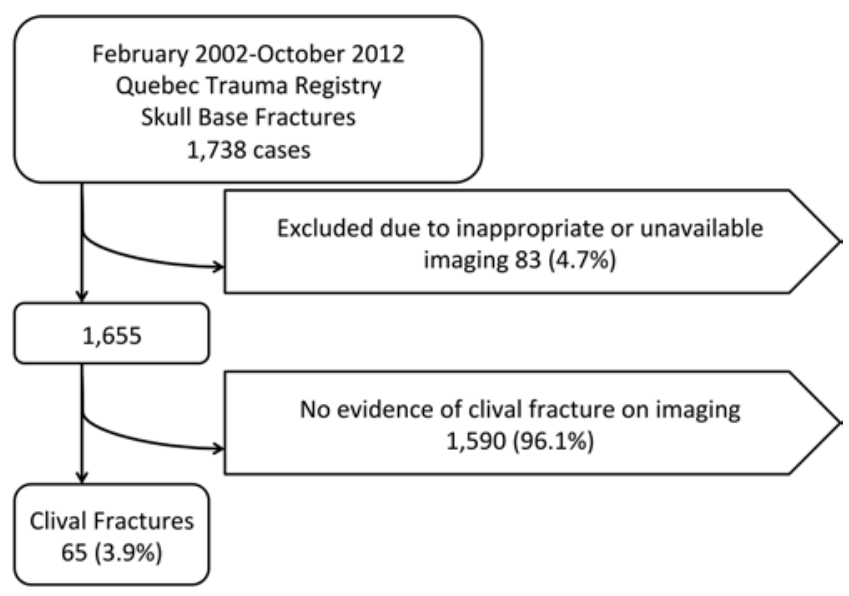

FIG. 4. Inclusion/exclusion flowchart for CF study.

and was performed in $16(24.6 \%)$ patients, representing $6(66.7 \%)$ transverse, $8(20.5 \%)$ oblique, and $2(11.8 \%)$ longitudinal fracture orientations; of these, $5(55.5 \%)$ had displaced, 8 (27.6\%) linear, 2 (11.8\%) hairline, and 1 $(10 \%)$ diastatic fracture qualities. In 1 case, surgical intervention was required to free the infraorbital nerve during a frontal bone reconstruction surgery. The single case of CSF leak requiring surgical repair was due to a frontal sinus as opposed to skull base fracture.

\section{Outcome}

Twenty-five patients (38.5\%) died during hospitalization, representing $6(66.7 \%)$ transverse, 7 (41.2\%) longitudi- nal, and 12 (30.8\%) oblique CF orientations and $13(44.8 \%)$ linear, 6 (60\%) diastatic, 4 (23.5\%) hairline, and 2 (22.2\%) displaced CF qualities. Within the transverse orientation, fractures were more frequently fatal, irrespective of quality: $1(100 \%)$ hairline, $1(100 \%)$ linear, $3(75 \%)$ diastatic, and $1(33.3 \%)$ displaced. This was in contrast with longitudinal, where only 1 (33.3\%) hairline, 3 (42.5\%) linear, 3 $(60 \%)$ diastatic, and 0 displaced were fatal. Oblique fractures were also less fatal, with $2(15.3 \%)$ hairline, 9 (42.9\%) linear, 0 diastatic, and 1 (25\%) displaced being fatal. The median follow-up time was 4 (IQR 2-8) months. Table 5 presents the distribution of EGOS scores among the CF categories. Among survivors, hospitalization time ranged from 2 to 237 days. In 2 cases hospitalization time was 227 and 237 days, due to infectious complications.

\section{Clinical Scores}

The 2-way ANCOVA, adjusting for age, showed that the mean ISS increased from the longitudinal $(29.8 \pm 2.4)$, to oblique $(32.3 \pm 2)$, to transverse $(39.4 \pm 3.5)$ fracture orientation categories, but the differences were not statistically significant $[\mathrm{F}(2,52)=2.5, \mathrm{p}=0.09$; Table 6]. Furthermore, the mean ISS increased from the linear (30.8 $\pm 2.3)$, to hairline $(31.2 \pm 2.9)$, to diastatic $(33.7 \pm 3.2)$, to displaced $(39.6 \pm 3.2)$ fracture quality categories, but the differences were not statistically significant $[F(3,52)=1.7$, $\mathrm{p}=0.18$; Table 7].

The 2-way ANCOVA to compare the mean GCS score on admission to hospital among the groups showed a bimodal distribution of residuals, with clustering around

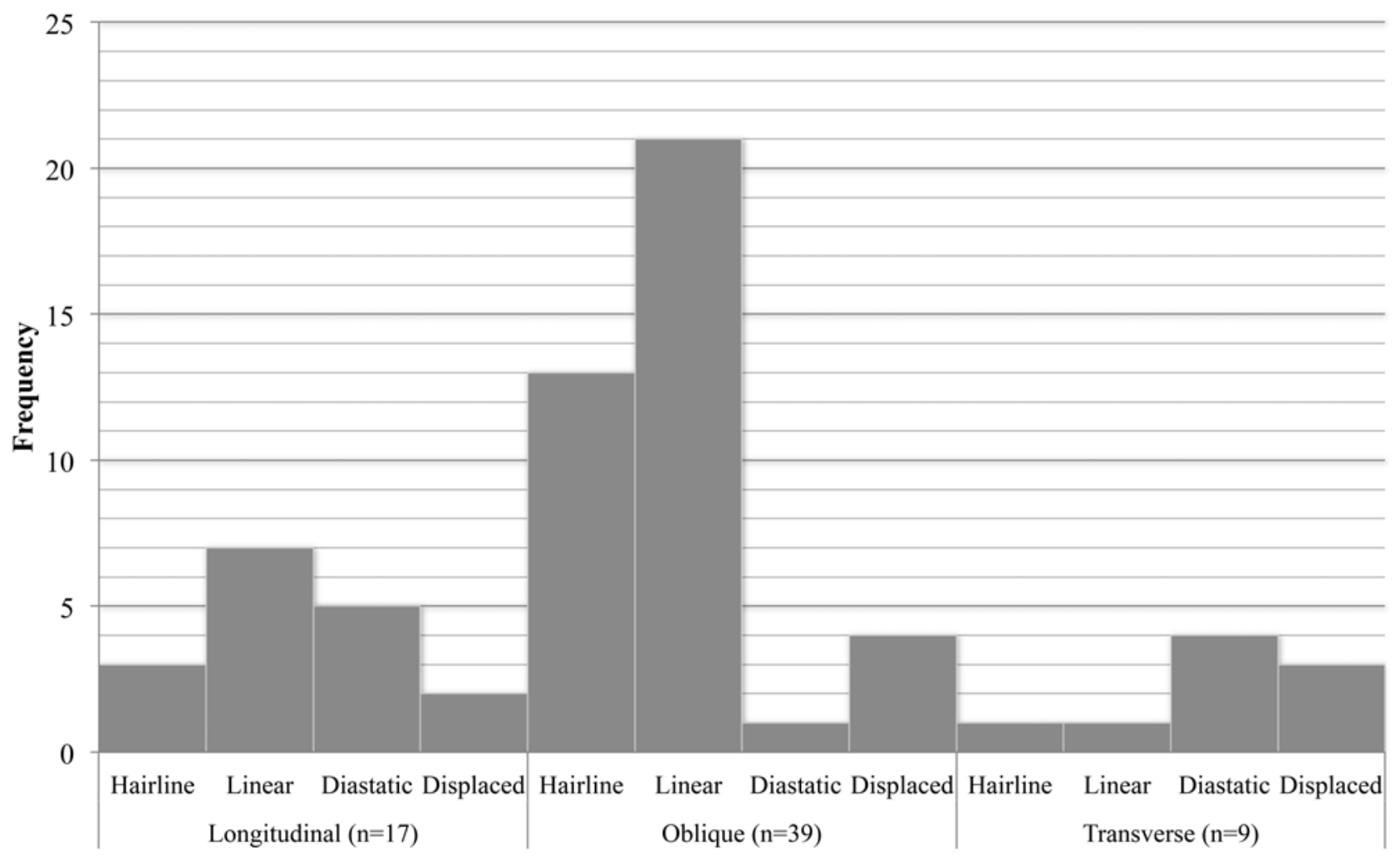

FIG. 5. Bar graph showing distribution of CF subtypes (hairline, linear, diastatic, displaced) among clival fracture orientations (longitudinal, oblique, transverse). 
TABLE 1. Characteristics of 65 patients in the CF group

\begin{tabular}{cc}
\hline \multicolumn{1}{c}{ Characteristic } & Value (\%) \\
\hline Median age in yrs, IQR & $38,26-56$ \\
\hline Male sex & $50(76.9)$ \\
\hline Mechanism of injury & $6(9.2)$ \\
\hline Fall from own height & $25(38.4)$ \\
\hline Fall from height & $13(20.0)$ \\
\hline Pedestrian vs motor vehicle & $15(23.0)$ \\
\hline MVA & $4(6.1)$ \\
\hline Assault & $2(3.0)$ \\
\hline Other* & $6,3-13$ \\
\hline Median GCS score, IQR & $21(32.3)$ \\
\hline Mild; $13-15$ & $6(9.2)$ \\
\hline Moderate; $9-12$ & $38(58.4)$ \\
\hline Severe; $3-8$ & $31.4 \pm 9.9,10-57$ \\
\hline Mean ISS \pm SD, range† & 0 \\
\hline Minor; $<9$ & $2(3.3)$ \\
\hline Moderate; $9-14$ & $8(13.6)$ \\
\hline Moderate/severe; $15-24$ & $49(83.0)$ \\
\hline Severe/critical; $>25$ &
\end{tabular}

* Tobogganing accident and exiting a moving vehicle.

$\dagger$ The ISS was not available in 6 cases.

GCS 3 and 15, respectively. Therefore, comparisons of mean GCS scores among CF quality and CF orientations were not performed, and only age-adjusted means and SDs are reported. The mean GCS score decreased from

TABLE 2. Associated injuries among 65 patients in the CF group

\begin{tabular}{lc}
\hline \multicolumn{1}{c}{ Characteristic } & No. $(\%)$ \\
\hline Cranial nerve deficit & $9(13.8)$ \\
\hline CSF leak & $5(7.7)$ \\
\hline Vascular injury & $5(7.7)$ \\
\hline Fractures & \\
\hline Frontal & $18(27.7)$ \\
\hline Temporal/petrous & $31(47.7)$ \\
\hline Parietal & $10(15.3)$ \\
\hline Occipital & $51(78.4)$ \\
\hline Sellar/carotid & $29(44.6)$ \\
\hline Cervical spine & $5(7.7)$ \\
\hline Intracranial hemorrhage & $8(12.3)$ \\
\hline Epidural & $57(87.7)$ \\
\hline Subdural & $54(83.0)$ \\
\hline Subarachnoid & $19(29.2)$ \\
\hline Intraventricular & $53(81.5)$ \\
\hline Hemorrhagic contusion (excluding brainstem) & $12(18.4)$ \\
\hline Brainstem & 0 \\
\hline Retroclival hematoma & \\
\hline Herniation syndromes & $13(20.0)$ \\
\hline Falcine & $21(32.3)$ \\
\hline Uncal & $9(13.8)$ \\
\hline Tonsillar &
\end{tabular}

TABLE 3. Cranial nerve and vascular injuries among specific CF subtypes

\begin{tabular}{lll}
\hline Structure Damaged & \multicolumn{1}{c}{ CF Type } & Specific Deficit \\
\hline Cranial nerve & Longitudinal hairline & Rt III \\
\hline & Longitudinal displaced & Lt VI, It VIII \\
\hline & Oblique hairline & Rt VI \\
\hline & Oblique hairline & Lt IV, rt V1-3 \\
\hline & Oblique linear & Lt VI \\
\hline & Oblique linear & Lt VI, rt VII \\
\hline & Oblique displaced & Lt III, II \\
\hline & Oblique displaced & Rt VII, VIII \\
\hline & Transverse diastatic & IV, VI* \\
\hline Vascular structure & Longitudinal diastatic & Carotid \\
\hline & Oblique hairline & Vertebral \\
\hline & Oblique linear & Vertebral \\
\hline & Oblique linear & Carotid \\
\hline & Transverse diastatic & Carotid \\
\hline &
\end{tabular}

* Localization not available.

the oblique $(9 \pm 0.9)$, to longitudinal $(8.2 \pm 1.1)$, to transverse $(4.1 \pm 1.5)$ fracture orientation categories. Furthermore, the GCS score decreased from the displaced (9.2 \pm $1.5)$, to hairline $(8.4 \pm 1.2)$, to linear $(6.4 \pm 1)$, to diastatic $(4.4 \pm 1.5)$ fracture quality categories.

The 2-way ANCOVA, adjusting for age, showed statistically significant differences in mean EGOS scores according to $\mathrm{CF}$ orientation $[\mathrm{F}(2,58)=4.1, \mathrm{p}=0.02]$ and $\mathrm{CF}$ quality $[\mathrm{F}(3,58)=2.9, \mathrm{p}=0.04]$, respectively. There was no interaction between $\mathrm{CF}$ orientation and $\mathrm{CF}$ quality, meaning that the effect of each of these factors on the mean EGOS score was independent of the others. The mean EGOS score decreased from the longitudinal ( $4.8 \pm$ $0.6)$, to oblique $(4.7 \pm 0.5)$, to transverse $(2.2 \pm 0.8)$ fracture orientation categories. The mean EGOS score was significantly lower in the transverse versus both longitudinal and oblique $\mathrm{CF}$ orientations (both $\mathrm{p}=0.03$; Table 6). Furthermore, the mean EGOS score decreased from the displaced $(5.2 \pm 0.8)$, to hairline $(4.3 \pm 0.6)$, to linear (3.5 $\pm 0.5)$, to diastatic $(2.4 \pm 0.8)$ fracture quality categories. The mean EGOS score was lower in diastatic versus displaced CF quality $(\mathrm{p}=0.05$; Table 7$)$.

\section{Discussion}

\section{Incidence of CFs}

Our study sought to identify unique clinical features among CF types to provide a better understanding of the

TABLE 4. Interventions among 65 patients in the CF group

\begin{tabular}{lc}
\hline \multicolumn{1}{c}{ Characteristic } & No. $(\%)$ \\
\hline Cranial nerve repair & $1(1.5)$ \\
\hline CSF leak repair & $1(1.5)$ \\
\hline Exploratory bur hole & $1(1.5)$ \\
\hline Craniotomy & $2(3.0)$ \\
\hline Decompressive craniectomy & $16(24.6)$ \\
\hline
\end{tabular}


TABLE 5. Outcome at latest follow-up among 65 patients in the CF group*

\begin{tabular}{ccccccccc}
\hline EGOS Score & Entire Cohort & Longitudinal & Oblique & Transverse & Hairline & Linear & Displaced & Diastatic \\
\hline 1 & $25(38.5)$ & $7(41.2)$ & $12(30.8)$ & $6(66.7)$ & $4(23.5)$ & $13(44.8)$ & $2(22.2)$ & $6(60.0)$ \\
\hline 2 & $1(1.5)$ & $1(5.9)$ & 0 & 0 & 0 & $1(3.4)$ & 0 & 0 \\
\hline 3 & 0 & 0 & 0 & 0 & 0 & 0 & 0 & 0 \\
\hline 4 & $5(7.7)$ & 0 & $3(7.7)$ & $2(22.2)$ & $1(5.9)$ & $2(6.9)$ & $1(11.1)$ & $1(10.0)$ \\
\hline 5 & $3(4.6)$ & 0 & $3(7.7)$ & 0 & $1(5.9)$ & $2(6.9)$ & 0 & 0 \\
\hline 6 & $11(16.9)$ & $2(11.8)$ & $9(23.1)$ & 0 & $4(23.5)$ & $4(13.8)$ & $3(33.3)$ & 0 \\
\hline 7 & $10(15.4)$ & $3(17.6)$ & $7(17.9)$ & 0 & $4(23.5)$ & $3(10.3)$ & $1(11.1)$ & $2(20.0)$ \\
\hline 8 & $10(15.4)$ & $4(23.5)$ & $5(12.8)$ & $1(11.1)$ & $3(17.6)$ & $4(13.8)$ & $2(22.2)$ & $1(10.0)$ \\
\hline Total & $65(100)$ & $17(26.1)$ & $39(60.0)$ & $9(13.8)$ & $17(26.1)$ & $29(44.6)$ & $9(13.8)$ & $10(15.4)$ \\
\hline
\end{tabular}

* Data presented as number (\%).

pathogenesis and outcome in these injuries. To date, this represents the largest cohort of patients with CF studied in the literature. We demonstrate an incidence of $1.2 \%$ among TBI victims admitted to hospital. This incidence is higher than previously reported. Indeed, previous estimates of $\mathrm{CF}$ have shown an incidence among head trauma patients of $0.21 \%^{33}$ and $0.56 \%$ in an adult population admitted to hospital. Another study showed an incidence of $0.36 \%,{ }^{29}$ but the base population was not defined. The reported incidence in a pediatric population is $0.4 \% .^{32} \mathrm{~A}$ smaller pool of head traumas, ${ }^{7,29}$ as well as use of Boolean search terms of dictated radiographic reports to identify $\mathrm{CF}^{32,33}$ may account for underreporting of $\mathrm{CF}$ incidence. By having a referral population of $1,125,425$, a preexisting trauma database to identify skull base fractures, and reviewing all imaging and radiographic reports, we ensured the most accurate and complete rate of $\mathrm{CF}$ detection. Our estimated prevalence does not, however, take into account trauma victims who died before ever reaching our institution.

\section{Subtypes and Pathogenesis of CF}

Our findings suggest that the most commonly occurring $\mathrm{CFs}$, in order of decreasing frequency, were oblique, longitudinal, and transverse. These findings are similar to those in the largest series to date, consisting of 41 patients, published in 2009 by Ochalski et al., ${ }^{33}$ whereas smaller case series have described an equal incidence of longitudinal, oblique, and transverse $\mathrm{CF}^{7,32}$

Skull base fractures are thought to occur due to transmitted forces that occur at times at a substantial distance from the point of maximal impact. ${ }^{10}$ Cadaveric studies have demonstrated that applying a crushing force to the skull laterally produces fractures along the petrous bone, in some cases extending transversely into the clivus, whereas anteroposterior compression causes longitudinal fractures along the skull base. ${ }^{38}$ In addition, authors have proposed a mechanism whereby posterior blows cause lateral expansion of the posterior fossa, creating an extended fracture. ${ }^{7}$ Similarly, in our study temporal/ petrous fractures were implicated in the majority of transverse fractures, frontal fractures were involved in more than half of longitudinal fractures, and oblique fractures were often the result of extension of occipital fractures into the clival complex. Previous authors have identified a preponderance for petrous fractures in cases of transverse and oblique fractures, ${ }^{7}$ whereas others have postulated that impacts directed in the middle of the sagittal plane of the skull cause longitudinal $\mathrm{CF}^{44}$ Oblique $\mathrm{CF}^{24}$ and transverse $\mathrm{CF}^{14}$ resulting from occipital fracture extension have also been described in the literature, with a further 4 cases describing $C F$ with associated occipital fracture. $5,8,17,45$

Interestingly, ISS and proportion of MVAs increased from hairline, to linear, to diastatic and finally to displaced CF type. It is clear that these fractures result from high-impact trauma, and previous authors have demonstrated forces of $4300 \mathrm{~N}$ required to produce fractures of the skull base. ${ }^{27}$ Therefore, the results of our study suggest that CF orientation can be thought of as an indicator of impact location ("where"), whereas quality of fracture may reflect the intensity of force applied ("how much").

TABLE 6. Multiple comparisons and mean differences in EGOS and ISS by CF orientation

\begin{tabular}{clccc}
\hline Scale & \multicolumn{1}{c}{ Comparison* $^{*}$} & Mean Difference & $95 \% \mathrm{Cl}$ & $\mathrm{p} \mathrm{Value}$ \\
\hline EGOS & & & & 0.99 \\
\hline & Longitudinal vs oblique & 0.1 & $-1.6,1.8$ & 0.03 \\
\hline & Longitudinal vs transverse & 2.6 & $0.3,4.9$ & 0.03 \\
\hline ISS & Oblique vs transverse & 2.5 & $0.2,4.8$ & 0.67 \\
\hline & & & $-9.8,4.7$ & 0.07 \\
\hline & Longitudinal vs oblique & -2.5 & $-20.0,0.7$ & 0.25 \\
\hline
\end{tabular}

* Comparisons based on ANCOVA adjusted means controlling for age. 
TABLE 7. Multiple comparisons and mean differences in EGOS and ISS by CF quality

\begin{tabular}{clccc}
\hline Scale & \multicolumn{1}{c}{ Comparison* $^{*}$} & Mean Difference & $95 \% \mathrm{Cl}$ & $\mathrm{p} \mathrm{Value}$ \\
\hline EGOS & & & $-5.7,0$ & 0.05 \\
\hline & Diastatic vs displaced & -2.9 & $-3.7,1.5$ & 0.65 \\
\hline & Diastatic vs linear & -1.1 & $-4.7,0.7$ & 0.23 \\
\hline & Diastatic vs hairline & -1.9 & $-0.7,4.1$ & 0.24 \\
\hline & Displaced vs linear & 1.7 & $-1.7,3.4$ & 0.78 \\
\hline Displaced vs hairline & 0.9 & $-1.0,2.7$ & 0.65 \\
\hline & Hairline vs linear & 0.8 & & 0.58 \\
\hline & & & $-18.0,6.3$ & 0.90 \\
\hline & Diastatic vs displaced & -5.8 & $-8.3,14.1$ & 0.94 \\
\hline & Diastatic vs linear & 2.9 & $-9.4,14.5$ & 0.14 \\
\hline & Diastatic vs hairline & 2.6 & $-1.8,19.3$ & 0.23 \\
\hline & Displaced vs linear & 8.7 & $-3.1,20.0$ & 0.99 \\
\hline
\end{tabular}

\section{Outcome}

In our group, 25 patients (38.5\%) died during their hospitalization. This estimate is higher than recent studies in which mortality ranged between $24 \%$ and $31 \% .29,33$ This difference may reflect the high severity of traumas in our study population. Because our institution is a Level I trauma center, the proportion of patients who had sustained critical injuries and aggressive interventions is much higher than previously described.$^{33}$ In addition, we demonstrate a significant decrease in EGOS scores in transverse and diastatic CF, when corrected for age. Case reports ${ }^{7,29}$ have often cited longitudinal fractures as being mortality prone; however, this may represent bias from the large number of postmortem case reports prior to frequent use of CT technology, or sampling error from small case series. ${ }^{29}$ Our findings indicate that transversely oriented fractures have a higher associated mortality. These findings are in keeping with Ochalski et al.'s study, in which $66 \%$ of patients with transverse CF died, the highest among any orientation group. In addition, our results suggest that transversely oriented fractures and diastatic fractures carry among the worst prognoses when considering initial hospital mortality and postdischarge functional improvement. However, it should be noted that full recovery (EGOS Score 8) was achieved in 1 case each of diastatic and transverse CF (see Table 5).

Somewhat unexpectedly, despite the highest average ISS and greatest proportion of MVAs, displaced fractures had among the best outcomes within CF quality types, with two-thirds of patients achieving an EGOS score of at least 6 on follow-up and a mortality rate of $22 \%$, which was the lowest among CF quality groups. This remains in stark contrast to patients with diastatic fracture, who themselves also have high ISSs and a high proportion of MVAs, but have the worst prognosis within CF qualities, with $66 \%$ mortality. Although most CF quality types had similarly high levels of concomitant hemorrhagic contusions, displaced fractures had among the lowest rates of brainstem hemorrhage. It may be the case that, in addi- tion to providing physical support, the clivus may serve to redirect damaging biomechanical forces, thus sparing the brainstem from damage. Furthermore, it appeared that displaced CFs had a greater number of avulsion fractures of the clival region compared with diastatic. These findings may reflect a different mechanism of injury, whereby displaced fractures have a higher propensity for injury due to rotational force, causing ligamentous failure and chipping of the clivus while sparing surrounding structures.

\section{Associated Injuries}

In keeping with the literature, cranial nerve deficits usually occurred in oblique or transverse fractures. Although oftentimes multiple cranial nerves were implicated, there were no cases of bilateral sixth nerve palsy, as previously reported. ${ }^{22,24,29}$ Interestingly, displaced fractures were implicated in 2 cases of posttraumatic deafness. This may be due to either high force of impact causing increased shearing forces on the nerve, or compression of the nerve itself by movement of the skull fracture. In addition, vascular injury was most often implicated in oblique or transverse orientations (Table 3). Longitudinal CFs have been traditionally implicated in basilar artery entrapment, $3,12,44$ and oblique or transverse fractures have been often implicated in damage to the carotid arteries. ${ }^{7,24,29,33}$ Somewhat unexpectedly, there were no instances of basilar artery entrapment in our cohort. Given that an angiographic study was performed in $66 \%$ of cases, some instances of vascular injury may have been missed.

\section{Strengths and Limitations of the Study}

By virtue of a large referral population, a high-quality, province-wide trauma registry validated to detect severe injuries, and a systematic review of all relevant imaging and radiology reports of skull base fractures admitted to our institution, we ensured the detection of the greatest number of CFs. Furthermore, our study is among the first to introduce postdischarge follow-up in this condition, thus expanding our current understanding of the longterm morbidity in these rare fractures. 
Weaknesses in our study include limitations associated with retrospective observational studies-namely issues of data quality in the chart review process; lack of identification of other potential confounding factors, such as pretrauma comorbid conditions; and limited follow-up information. Also, changes in treatment algorithms over the interval of this 10-year study may have influenced outcome. Future directions for study are to include a larger population sample, making comparisons within $\mathrm{CF}$ orientations possible.

\section{Conclusions}

This study provides information on the largest CF population studied to date and expands current CF classification to include fracture quality as well as orientation. It reveals a higher CF incidence than previously reported. It confirms a higher mortality rate for transverse fractures and shows that diastatic fractures are associated with a worse outcome compared with other fracture quality types. Greater injury severity, higher impact factor, and poorer long-term outcome were associated with transverse and diastatic fractures; whereas oblique and linear fractures were more common, not requiring as much velocity to form and carrying a better prognosis. Displaced fractures carried the best long-term prognosis.

\section{References}

1. Anthony DC, Atwater SK, Rozear MP, Burger PC: Occlusion of the basilar artery within a fracture of the clivus. Case report. J Neurosurg 66:929-931, 1987

2. Baker SP, O'Neill B, Haddon W Jr, Long WB: The injury severity score: a method for describing patients with multiple injuries and evaluating emergency care. J Trauma 14:187196,1974

3. Bala A, Knuckey N, Wong G, Lee GY: Longitudinal clivus fracture associated with trapped basilar artery: unusual survival with good neurological recovery. J Clin Neurosci 11:660-663, 2004

4. Bonilha L, Fernandes YB, Mattos JP, Borges WA, Borges G: Bilateral internuclear ophthalmoplegia and clivus fracture following head injury: case report. Arq Neuropsiquiatr 60 (3-A):636-638, 2002

5. Buyukkaya R, Buyukkaya A, Ozturk B, Saritas A: Complex fracture of the clivus after head trauma. Am J Emerg Med 32:486.e1-486.e3, 2014

6. Carter LP, Pittman HW: Posterior fossa subdural hematoma of the newborn. Case report. J Neurosurg 34:423-426, 1971

7. Corradino G, Wolf AL, Mirvis S, Joslyn J: Fractures of the clivus: classification and clinical features. Neurosurgery 27:592-596, 1990

8. Dashti R, Ulu MO, Albayram S, Aydin S, Ulusoy L, Hanci $\mathrm{M}$ : Concomitant fracture of bilateral occipital condyle and inferior clivus: what is the mechanism of injury? Eur Spine J 16 (Suppl 3):261-264, 2007

9. de Melo PM, Kadri PA, de Oliveira JG, Suriano IC, Cavalheiro S, Braga FM: Cervical epidural haematoma with clivus fracture: case report. Arq Neuropsiquiatr 61 (2B):499-502, 2003

10. Dolan KD, Jacoby CG: Radiology of basilar skull fractures. CRC Crit Rev Diagn Imaging 12:101-152, 1979

11. Evers JJ, Vieth VV, Hartensuer RR, Raschke MM, Vordemvenne TT: Management of an extended clivus fracture: a case report. BMC Res Notes 6:554, 2013

12. García-García J, Villar-Garcia M, Abad L, Segura T: Brain- stem infarct due to traumatic basilar artery entrapment caused by longitudinal clival fracture. Arch Neurol 69:662663, 2012

13. Geisler FH, Rodriguez E, Manson PN: Traumatic skull and facial fractures, in Ellenbogen RG, Abdulrauf SI, Sekhar LN (eds): Principles of Neurological Surgery, ed 3. Philadelphia: Elsevier Saunders, 2012, pp 365-393

14. Grossbach AJ, Abel TJ, Menezes AH, Howard MA: Transverse clival fracture associated with bilateral petrous fractures extending through the occipital bone. Case illustration. J Neurosurg 118:775, 2013

15. Guha A, Fazl M, Cooper PW: Isolated basilar artery occlusion associated with a clivus fracture. Can J Neurol Sci 16:81-83, 1989

16. Heggeness MH, Gannon FH, Weinberg J, Ben-Galim P, Reitman CA: Orthopedic surgery, in Brunicardi F, Andersen DK, Billar TR, et al (eds): Schwartz's Principles of Surgery, ed 9. New York: McGraw-Hill, 2010

17. Imamura T, Kojima T, Yashiki M, Namera A: Traumatic avulsion fracture of the occipital condyles and clivus: a case report. Leg Med (Tokyo) 2:49-53, 2000

18. Jennett B, Snoek J, Bond MR, Brooks N: Disability after severe head injury: observations on the use of the Glasgow Outcome Scale. J Neurol Neurosurg Psychiatry 44:285293, 1981

19. Jones DN, Knox AM, Sage MR: Traumatic avulsion fracture of the occipital condyles and clivus with associated unilateral atlantooccipital distraction. AJNR Am J Neuroradiol 11:1181-1183, 1990

20. Joslyn JN, Mirvis SE, Markowitz B: Complex fractures of the clivus: diagnosis with CT and clinical outcome in 11 patients. Radiology 166:817-821, 1988

21. Kapila A, Chakeres DW: Clivus fracture: CT demonstration. J Comput Assist Tomogr 9:1142-1144, 1985

22. Katsuno M, Yokota H, Yamamoto Y, Teramoto A: Bilateral traumatic abducens nerve palsy associated with skull base fracture-case report. Neurol Med Chir (Tokyo) 47:307309, 2007

23. Khan N, Zumstein B: Transverse clivus fracture: case presentation and significance of clinico-anatomic correlations. Surg Neurol 54:171-177, 2000

24. Kim SH, Kim SW: Sixth and twelfth cranial nerve palsies following basal skull fracture involving clivus and occipital condyle. J Korean Neurosurg Soc 51:305-307, 2012

25. Loop JW, White LE Jr, Shaw CM: Traumatic occlusion of the basilar artery within a clivus fracture. Radiology 83:36-40, 1964

26. Masopust V, Plas J: [Longitudinal fractures of the clivus.] Rozhl Chir 77:385-388, 1998 (Czech)

27. McElhaney JH, Hopper RH Jr, Nightingale RW, Myers BS: Mechanisms of basilar skull fracture. J Neurotrauma 12:669-678, 1995

28. Meguro K, Rowed DW: Traumatic aneurysm of the posterior inferior cerebellar artery caused by fracture of the clivus. Neurosurgery 16:666-668, 1985

29. Menkü A, Koç RK, Tucer B, Durak AC, Akdemir H: Clivus fractures: clinical presentations and courses. Neurosurg Rev 27:194-198, 2004

30. Moore L, Lavoie A, Sirois MJ, Amini R, Belcaïd A, Sampalis JS: Evaluating trauma center process performance in an integrated trauma system with registry data. J Emerg Trauma Shock 6:95-105, 2013

31. Morris A, Welsh R, Hassan A: Requirements for the crash protection of older vehicle passengers. Annu Proc Assoc Adv Automot Med 47:165-180, 2003

32. Ochalski PG, Adamo MA, Adelson PD, Okonkwo DO, Pollack IF: Fractures of the clivus and traumatic diastasis of the central skull base in the pediatric population. Clinical article. J Neurosurg Pediatr 7:261-267, 2011 
33. Ochalski PG, Spiro RM, Fabio A, Kassam AB, Okonkwo DO: Fractures of the clivus: a contemporary series in the computed tomography era. Neurosurgery 65:1063-1069, 2009

34. Ogungbo B, Sengupta R: Traumatic fracture of the clivus and vermian contusion in a child. Br J Neurosurg 15:159-161, 2001

35. Ono H, Uchida M, Tanaka Y, Tanaka K, Hashimoto T: Traumatic longitudinal clival fracture in a child-case report. Neurol Med Chir (Tokyo) 51:707-710, 2011

36. Paterakis KN, Karantanas AH, Hadjigeorgiou GM, Anagnostopoulos V, Karavelis A: Retroclival epidural hematoma secondary to a longitudinal clivus fracture. Clin Neurol Neurosurg 108:67-72, 2005

37. Portier F, Salvan D, Duruisseau O, Herman P, Tran Ba Huy P: A rare clival and sellar fracture with pneumatocephalus. Auris Nasus Larynx 29:195-198, 2002

38. Russell WR, Schiller F: Crushing injuries to the skull; clinical and experimental observations. J Neurol Neurosurg Psychiatry 12:52-60, 1949

39. Sanders BB, VanderArk GD: Transverse fracture of the clivus. J Neurosurg 39:610-614, 1973

40. Santé et Services sociaux Québec: Projections de la population du Québec selon le territoire de réseau local de services (RLS), le sexe, l'âge et le groupe d'âge, 2006 à 2031 (Avril 2012). (http://www.informa.msss.gouv.qc.ca/Details. aspx?Id=vcuCWZHK870=) [Accessed September 4, 2014]

41. Sato H, Sakai T, Uemura K: [A case of incarceration of the vertebral and basilar arteries in a longitudinal fracture of the clivus.] No Shinkei Geka 18:1147-1150, 1990 (Jpn)

42. Sato S, Iida H, Hirayama H, Endo M, Ohwada T, Fujii K: Traumatic basilar artery occlusion caused by a fracture of the clivus-case report. Neurol Med Chir (Tokyo) 41:541-544, 2001

43. Sights WP Jr: Incarceration of the basilar artery in a fracture of the clivus. Case report. J Neurosurg 28:588-591, 1968

44. Taguchi Y, Matsuzawa M, Morishima H, Ono H, Oshima K, Hayakawa M: Incarceration of the basilar artery in a longitudinal fracture of the clivus: case report and literature review. J Trauma 48:1148-1152, 2000
45. Tanabe M, Watanabe T, Matsumoto S, Okamoto H, Shirakashi K: Avulsion fracture of the anterior half of the foramen magnum involving the bilateral occipital condyles and the inferior clivus - case report. Neurol Med Chir (Tokyo) 39:358-361, 1999

46. Tay BKB, Freedman BA, Rhee JM, Boden SD, Skinner HB: Disorders, diseases, and injuries of the spine, in Skinner HB, McMahon PJ (eds): Current Diagnosis \& Treatment in Orthopedics, ed 5. New York: McGraw-Hill, 2014, pp 156-229

47. Wang E: Clival fracture with basilar artery laceration. Curr Probl Diagn Radiol 41:114-115, 2012

48. Yavuz C, Sencer A, Kabataş S, Imer M, Kiriş T, Unal F: [Longitudinal clival fractures: a report of three cases.] Ulus Travma Acil Cerrahi Derg 12:321-325, 2006 (Turkish)

\section{Author Contributions}

Conception and design: Marcoux. Acquisition of data: Marcoux, Winkler-Schwartz. Analysis and interpretation of data: Marcoux, Winkler-Schwartz. Drafting the article: Winkler-Schwartz. Critically revising the article: Marcoux. Reviewed submitted version of manuscript: Winkler-Schwartz, Correa. Approved the final version of the manuscript on behalf of all authors: Marcoux. Statistical analysis: Winkler-Schwartz, Correa. Study supervision: Marcoux.

\section{Supplemental Information \\ Previous Presentation}

A portion of this manuscript has been published in abstract form in the proceedings of the Canadian Neurological Sciences Federation, 48th Annual Congress, 2013.

\section{Correspondence}

Judith Marcoux, Department of Neurology and Neurosurgery, McGill University, and Department of Neurosurgery, McGill University Health Centre, Rm. L7-516, Montreal General Hospital, 1650 Cedar Ave., Montreal, QC H3G 1A4, Canada. email: judith.marcoux@mcgill.ca. 